\title{
BMJ Open Occurrence, mortality and cost of brain disorders in Denmark: a population- based cohort study
}

\author{
Søren Viborg Vestergaard (1) , ${ }^{1}$ Thomas Bøjer Rasmussen (iD , 1 \\ Sandra Stallknecht (D) ,2 Jens Olsen, ${ }^{2}$ Niels Skipper (1) , ${ }^{3}$ Henrik Toft Sørensen (D) , 1 \\ Christian Fynbo Christiansen (i) ${ }^{1}$
}

To cite: Vestergaard SV, Rasmussen TB, Stallknecht S, et al. Occurrence, mortality and cost of brain disorders in Denmark: a populationbased cohort study. BMJ Open 2020;10:e037564. doi:10.1136/ bmjopen-2020-037564

- Prepublication history and supplemental material for this paper is available online. To view these files, please visit the journal online (http://dx.doi org/10.1136/bmjopen-2020 037564).

Received 07 February 2020 Revised 20 August 2020 Accepted 25 September 2020

Check for updates

(C) Author(s) (or their employer(s)) 2020. Re-use permitted under CC BY-NC. No commercial re-use. See rights and permissions. Published by BMJ.

${ }^{1}$ Department of Clinical Epidemiology, Aarhus University Hospital, Aarhus, Denmark ${ }^{2}$ Incentive, Holte, Denmark

${ }^{3}$ Department of Economics and Business Economics, Aarhus University, Aarhus, Denmark

Correspondence to

Dr Søren Viborg Vestergaard; sovi@clin.au.dk

\section{ABSTRACT}

Objectives To examine the occurrence of brain disorders (ie, neurological and mental disorders) in Denmark and mortality and cost of illness among affected persons.

Design Matched cohort study.

Setting We obtained routinely collected registry data on all Danish residents during 1995-2015.

Participants We identified all persons alive on 1 January 2015 with a diagnosis of 25 specific brain disorders (prevalent cohort) and all persons with an incident diagnosis during 2011-2015 (incident cohort). Each person was matched on age and sex with 10 persons from the general population without the brain disorder of interest.

Primary and secondary outcome measures Prevalence and incidence of hospital-diagnosed brain disorders, 1-year absolute and relative mortality, and attributable direct and indirect costs of illness compared with the corresponding matched cohorts.

Results We identified 1075081 persons with at least one prevalent brain disorder (any brain disorder) on 1 January 2015 , corresponding to $18.9 \%$ of the Danish population. The incidence rate of any brain disorder during 2011-2015 was 1349 per 100000 person-years (95\% Cl 1345 to 1353). One-year mortality after diagnosis was increased in persons with any brain disorder (HR 4.7, 95\% $\mathrm{Cl} 4.7$ to 4.8 ) and in persons in every group of specific brain disorders compared with the matched cohort from the general population. The total attributable direct costs of brain disorders in 2015 were $€ 5.2$ billion and total attributable indirect costs were $€ 11.2$ billion. Traumatic brain injury, stress-related disorders, depression and stroke were the most common brain disorders. Attributable costs were highest for depression, dementia, stressrelated disorders and stroke.

Conclusions One in five Danish residents alive on 1 January 2015 had been diagnosed with at least one brain disorder, and mortality was five times higher in persons with any diagnosed brain disorder than in the general population. We found high attributable direct and indirect costs of brain disorders.

\section{BACKGROUND}

Brain disorders, including both neurological and mental disorders, are the leading cause of years lived with disability worldwide. ${ }^{12}$ In
Strengths and limitations of this study

- We examined epidemiology and societal costs of hospital-diagnosed brain disorders using individuallevel data on a well-defined population with complete follow-up.

- Both epidemiology and cost were estimated among persons with one of 25 specific brain disorders, and among persons with any brain disorders taking into account comorbid disorders.

- We identified persons with incident brain disorders during 2011-2015, whereas persons alive on 1 January 2015 with brain disorders diagnosed from 1995 to 2014 were considered prevalent.

- We estimated 1-year mortality among persons with incident brain disorders, and direct and indirect societal costs among persons with prevalent brain disorders

- Direct costs included cost of services in primary care, secondary care and costs of medication, nursing home, sheltered accommodation, personal nursing, home nurse visits and hospital-based neurorehabilitation, whereas lost productivity was considered indirect costs.

2010, it was estimated that 260 million persons in Europe $(\sim 50 \%$ of the population) lived with a brain disorder with an estimated total cost-of-illness of $€ 798$ billion. ${ }^{3}{ }^{4}$ Based on this appraisal, mental disorders alone were estimated to account for $4.1 \%$ of European countries' combined gross domestic product (GDP) in $2015 .{ }^{5}$ The global burden of brain disorders is expected to double between 2010 and $2030 .{ }^{67}$

Previous estimates of overall occurrence and cost of brain disorders relied on heterogeneous data sources without individuallevel data. This excluded consideration of comorbid brain disorders in estimates of the incidence, prevalence, mortality and cost of illness of brain disorders. ${ }^{238}$ Therefore, single persons with multiple disorders were counted more than once, causing potential 
overestimation of the occurrence. Previous studies also focused on cause-specific mortality rather than all-cause mortality. This could have led to underestimation of excess mortality associated with brain disorders due to incompletely recorded brain disorders on death certificates. ${ }^{29}$ Thus, there is a need for valid updated estimates of occurrence, mortality and cost of brain disorders to better understand the public health burden and healthcare planning needs. ${ }^{7}$

We conducted this population-based study using routinely collected individual-level registry data to examine the prevalence and incidence of brain disorders in the Danish population during 2011-2015, as well as mortality and cost of illness in these patients.

\section{METHODS}

\section{Setting}

We conducted a population-based cohort study encompassing the entire Danish population during 2011-2015. In Denmark, healthcare is primarily tax-funded with equal access for every Danish resident. We examined occurrence, mortality and costs of brain disorders using nationwide data from healthcare and socioeconomic registries. ${ }^{10}$

\section{Study design and participants}

The following 25 predefined groups of brain disorders were examined: alcohol abuse, anxiety disorders, bipolar disorder, brain tumours, cerebral palsy, dementia, depression, developmental and behavioural disorders, drug abuse, eating disorders, epilepsy, headache, infections of the central nervous system, intellectual disability, multiple sclerosis, neuromuscular disorders, other neurodegenerative disorders, Parkinson's disease, personality disorders, polyneuropathy, schizophrenia spectrum disorders, sleep disorders, stress-related disorders, stroke and traumatic brain injury. Disorders were selected if expected to be common or critical, and we prioritised to select groups of disorders examined in previous studies to enable comparison of our results. ${ }^{23}$ For each of 25 specific brain disorders, we established two cohorts: a prevalent cohort of persons alive on 1 January 2015 who had a diagnosis of the specific brain disorder recorded during the 19952014 period and an incident cohort of persons with a firsttime diagnosis recorded during the 1 January 2011 to 31 December 2015 period. We also identified every Danish resident with any brain disorder, that is, each person with any of the specific 25 disorders was identified on the date of his or her first diagnosis. To avoid double counting, every person could only be included once in the any brain disorder cohort.

For each of the 25 specific brain disorder cohorts and the any brain disorder cohort, we created a matched comparison cohort for the incident cohort and a matched comparison cohort for the prevalent cohort. Each person in the brain disorder cohorts was matched to 10 living persons from the general population on birth year and sex (sampled with replacement). ${ }^{11}$ Matched persons could not have the brain disorder of interest as of the index date of the person with the brain disorder. The index dates of matching were the date of the brain disorder diagnosis for the incident cohort and 1 January 2015 for the prevalent cohort.

\section{Variables}

The unambiguous personal identifier assigned to every Danish resident enabled us to identify and link every person across national registries to estimate occurrence, mortality and cost of illness of brain disorders on the individual level (see detailed description of the data sources in online supplemental appendix 1). ${ }^{10}$

We identified persons with brain disorders by means of inpatient and outpatient hospital diagnoses (both primary and secondary diagnoses) coded in the Danish National Patient Registry according to the International Classification of Diseases, 10th Revision (ICD-10). ${ }^{12}$ ICD codes are provided in online supplemental appendix 2.

To estimate mortality, we retrieved the dates of death of persons who died during the study period from the Danish Civil Registration System. ${ }^{10}$

To estimate direct costs, we obtained individuallevel information on all primary care services provided by general practitioners and dentists from the Danish Health Service Registry, ${ }^{13}$ individual-level medication expenditures from the Danish National Prescription Registry, ${ }^{14}$ and individual-level information on nursing home or sheltered accommodation, personal nursing and other personal care, home nurse visits and hospitalbased neurorehabilitation from Statistics Denmark. ${ }^{15}$ We also computed costs of secondary care including hospital inpatient admissions, outpatient specialist clinic visits and emergency room contacts based on the Diagnosis Related Group (DRG) and Danish Ambulatory Grouping System (DAGS) tariffs. ${ }^{16}$ Medication costs were computed using market prices for prescriptions filled at outpatient pharmacies and in-hospital medication costs were included in the DRG/DAGS tariffs. To estimate indirect costs, we first estimated lost productivity associated with illness by subtracting the personal income of persons in the matched comparison cohorts from the personal income of persons with brain disorders (all before taxes). We then estimated lost productivity due to premature death (difference in actual age of death and expected age at death based on the average life expectancy of persons of same age and sex in Denmark). We obtained 2015 cost information for persons in the prevalent cohort and their comparison cohort and from index date for persons in the incident cohort and their comparison cohort.

Finally, we obtained information on prior comorbid brain disorders and on prior non-mental disorders included in the Charlson Comorbidity Index (CCI) up to 10 years before the index date of every person in the brain disorder and comparison cohorts. ${ }^{12}$ Using the comorbid diseases included in the CCI, we calculated a CCI score 

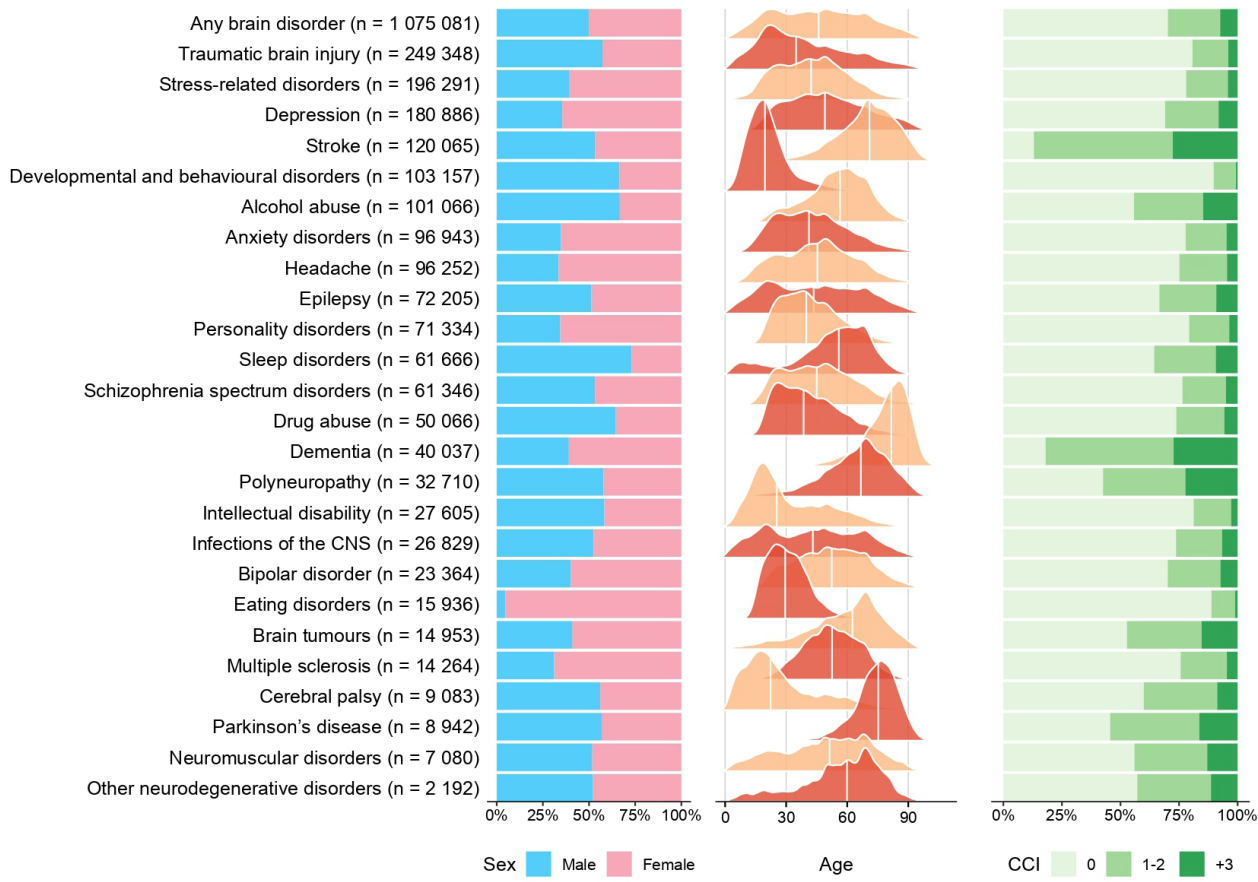

Figure 1 Characteristics of patients with prevalent brain disorders in Denmark in 2015 sorted from highest to lowest prevalence (the white line in the age distribution represents the median age in each cohort). CNS, central nervous system; CCI, Charlson Comorbidity Index.

for every person (CCI score: $0=$ low, 1-2=medium, 3+=high comorbidity). ${ }^{1718}$

\section{Statistical analyses}

\section{Occurrence}

We used any diagnosis from 1 January 1995 to 31 December 2014 as the basis for computing the period prevalence of each of the 25 brain disorders in persons alive on 1 January 2015. To estimate the average annual incidence of the different brain disorders, we computed incidence rates (IRs) of newly diagnosed persons per 100000 person-years at risk between 1 January 2011 and 31 December 2015. We considered a person to be at risk of an incident specific brain disorder only if he or she did not have a diagnosis of that specific brain disorder during 1995-2010. We characterised persons with brain disorders by age, sex, CCI conditions and CCI score on the index date across the 25 groups of disorders.

\section{Mortality}

We computed 1-year mortality for persons with brain disorders and for persons in their matched comparison cohorts and compared these by means of crude and adjusted HRs obtained from an unstratified Cox regression model adjusted for age, sex and CCI score.

\section{Cost of illness}

To estimate the economic burden of the 25 brain disorders, we used the human capital approach to conduct a societal cost-of-illness analysis including both direct and indirect individual-level costs. ${ }^{19}{ }^{20}$ For each brain disorder, we computed direct and indirect costs of illness for every individual in our study population. We estimated both overall annual costs and average annual costs per person. Direct costs were computed both as actual direct costs (ie, costs of healthcare services) and attributable direct costs (ie, the cost of healthcare services for persons with brain disorders minus the cost of healthcare services for persons of the same age and sex in the comparison cohorts). For persons with incident brain disorders, we further computed the distribution of the attributable direct costs per person during the first year after the diagnosis, as we expected substantial direct and indirect costs during this year.

We computed attributable indirect costs (ie, loss of productivity) in patients of working age, that is, ages $18-65$ years. In persons living with brain disorder diagnoses, we computed loss of productivity associated with illness as yearly income before taxes in persons with brain disorders subtracted from the yearly income in living members of the comparison cohorts. For persons who died after diagnoses of brain disorders, we estimated loss of productivity due to premature death as the annual income during the year before death multiplied by the number of lost years of life, assuming that they otherwise would have survived to age 66 years (accounting for the risk of dying each year and discounting future costs with $4 \%$ per annum). ${ }^{19} 20$

\section{Sensitivity analyses}

Patients with alcohol abuse, bipolar disorder, dementia, depression, drug abuse, headache, multiple sclerosis, Parkinson's disease and sleep disorders are commonly treated in general practice with medication specific for those disorders. Thus, we performed sensitivity analyses that included both persons with hospital diagnoses and persons who filled prescriptions for relevant pharmacological treatments of these disorders (including information on indication for the prescription when relevant). ${ }^{14}$ 
We repeated all occurrence and cost analyses on these extended cohorts.

In addition, we performed an ordinary least squares (OLS) regression to compute attributable direct costs, in which we modelled the average annual costs per person for each group of brain disorders. This OLS regression included every Danish resident (not only the matched cohorts) with age, sex and each of the 25 brain disorders as explanatory variables, and thus, costs of every brain disorder was adjusted for costs of comorbid brain disorders.

Analyses were performed using SAS V.9.4, and visualisation was made using Tidyverse packages in R V.3.6.1. ${ }^{21}$

\section{Patient involvement statement}

This study was done without patient involvement. Patients were not invited to comment on the study design, to develop patient relevant outcomes or interpret the results. Patients were not invited to contribute to the writing or editing of the manuscript.

\section{RESULTS}

\section{Patient characteristics}

The characteristics of 1075081 persons with prevalent brain disorders in 2015 are displayed in figure 1, and those of 381759 persons with incident brain disorders during 2011-2015 are displayed in online supplemental figure 1. Approximately half of persons with any brain disorder were female, occurrence was stable across ages, and three out of four persons had no or mild comorbidity (both in the prevalent and incident cohorts) (figure 1, online supplemental figure 1, online supplemental tables 1 and 2 ). The proportions of persons with specific brain disorders who were diagnosed with specific comorbid somatic or mental disorders before index date are displayed in online supplemental figure 2 .

\section{Occurrence}

On 1 January 2015, 18.9\% of the Danish population had been diagnosed with any brain disorder. Among persons without prior brain disorder diagnoses, the IR of any brain disorder was 1349 per 100000 person-years during 2011-2015 (online supplemental table 3).

The prevalence in 2015 and incidence in 2011-2015 of the 25 groups of brain disorders in the Danish population are displayed in figure 2. Traumatic brain disorders were the most common brain disorders, with a prevalence of $4.4 \%$ (figure 2 and online supplemental table 3 ), followed by stress-related disorders $(3.4 \%)$ and depression $(3.2 \%)$ (figure 2).

During 2011-2015, IRs were highest for stress-related disorders (286 per 100000 person-years (95\% CI 284 to 288) ) and depression (279 per 100000 person-years (95\% CI 277 to 281)) (figure 2 and online supplemental table 3).

\section{Mortality in persons with incident brain disorders}

One-year mortality was $7.8 \%$ among persons with any brain disorder, compared with $1.9 \%$ in the comparison cohort. After adjustment, persons with any brain disorder still had almost fivefold increased mortality (HR 4.7, 95\% CI 4.7 to 4.8 ), and the HRs were increased in every group of brain disorders. One-year mortality was highest in persons with other neurodegenerative disorders (28.0\%), brain tumours $(24.5 \%)$, stroke $(20.8 \%)$ and dementia $(20.3 \%)$. Of note, mortality was more than 10 -fold increased in persons with other neurodegenerative disorders (HR 15.3, 95\% CI 13.2 to 17.7), brain tumours (HR
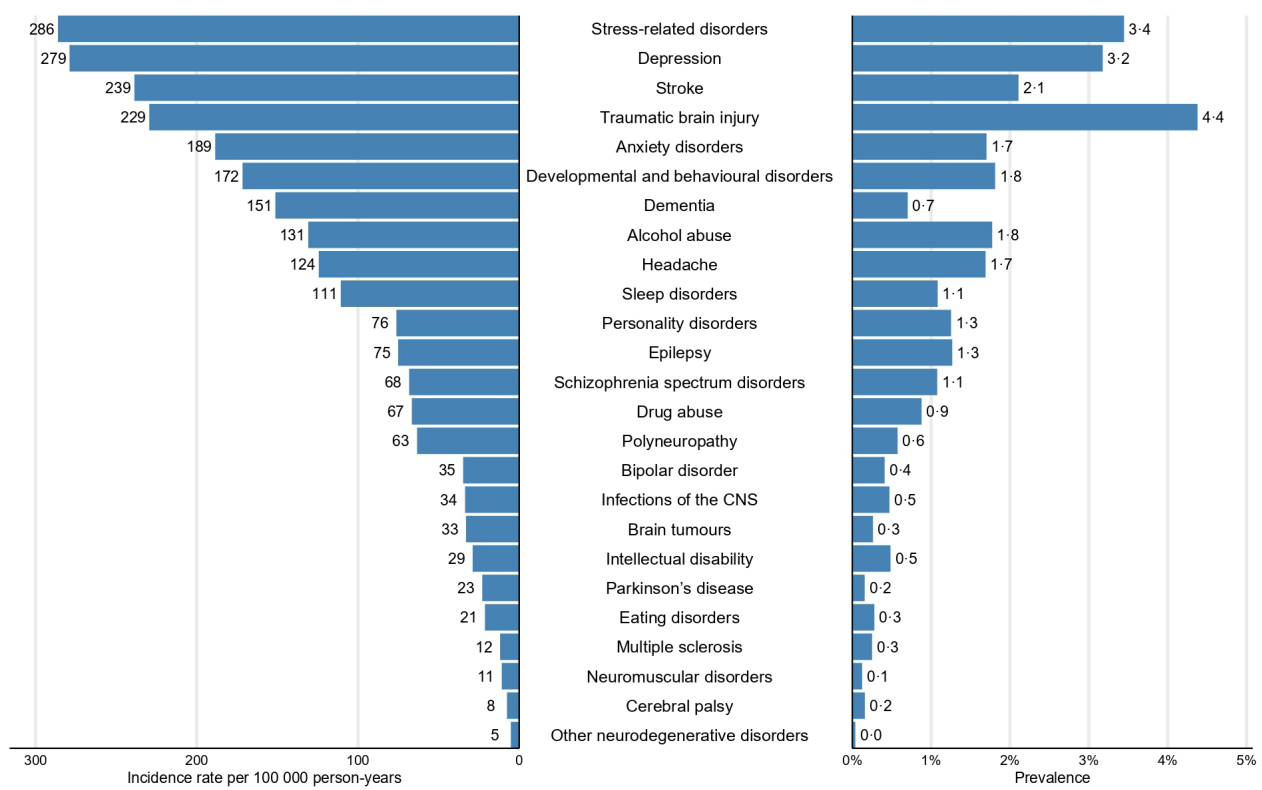

Figure 2 Occurrence of brain disorders in the Danish population sorted from highest to lowest incidence, including incidence during 2011-2015 and prevalence in 2015. CNS, central nervous system. 


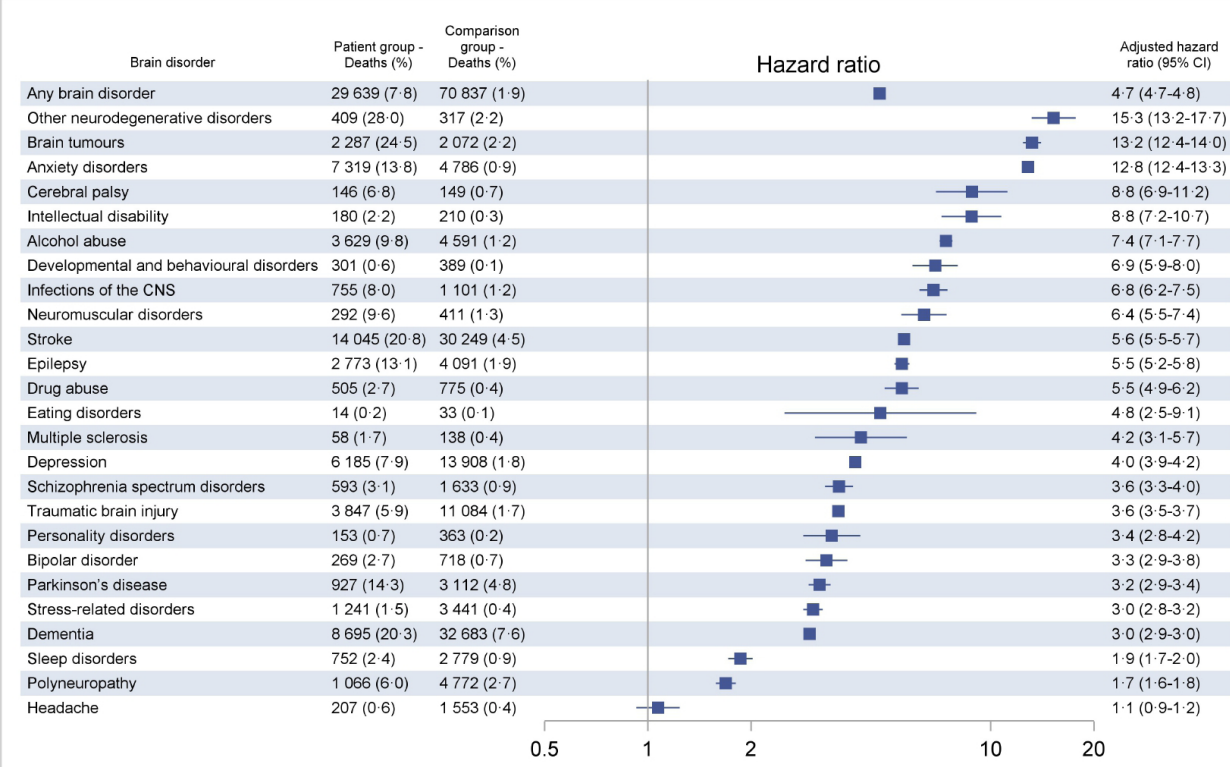

Figure 3 One-year mortality in patients with incident brain disorders in Denmark during 2011-2015 compared with the general population (comparison group). HRs are adjusted for age, sex and comorbidity score. Specific disorders are sorted by HRs.

CNS, central nervous system.

13.2, $95 \%$ CI 12.4 to 14.0 ) and anxiety disorders (HR $12.8,95 \%$ CI 12.4 to 13.3 ) (figure 3 ).

\section{Cost of illness}

The total direct attributable costs of any brain disorder were $€ 5.2$ billion in 2015 in Denmark, with increased costs in every group of brain disorders. Specifically, attributable direct costs were highest in patients with prevalent depression (€1.2billion), dementia ( $€ 1.1$ billion) and stroke (€1.0 billion) (figure 4 and online supplemental table 4). Importantly, the distribution of cost components varied considerably between brain disorders (figures 4 and 5).
Of note, the highest attributable costs per person in persons with prevalent brain disorders in 2015 was found in persons with dementia $(€ 30 \mathrm{~K})$ and Parkinson's disease $(€ 24 \mathrm{~K})$, mainly due to costs of nursing home/sheltered accommodation (figure 5 and online supplemental table 4).

The average attributable direct costs of any brain disorder during the first year after diagnosis was $€ 13 \mathrm{~K}$, though these differed widely between persons with different disorders. Costs were highest during the first year in persons with incident brain tumours (€44K) and schizophrenia spectrum disorders (€39K) (online

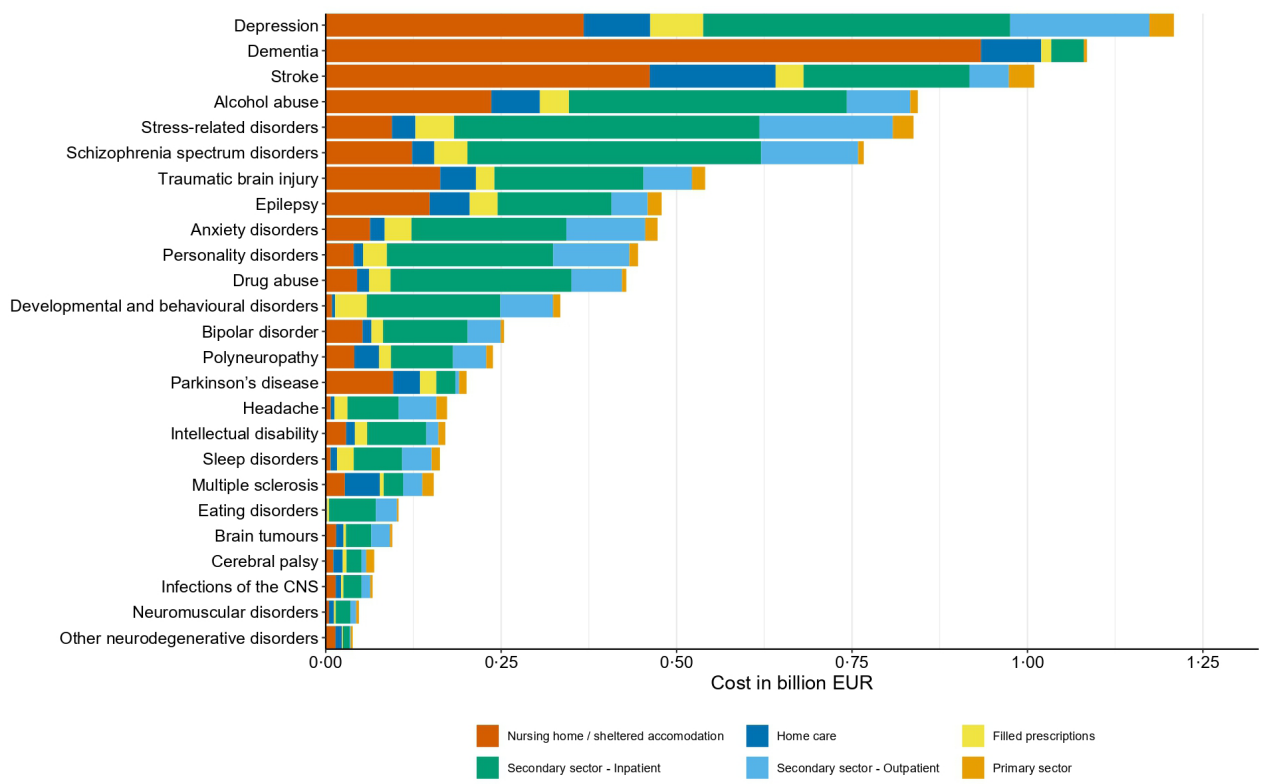

Figure 4 Total attributable direct costs in persons with prevalent brain disorders in Denmark in 2015 (in 2015 prices) sorted from highest to lowest costs. CNS, central nervous system. 


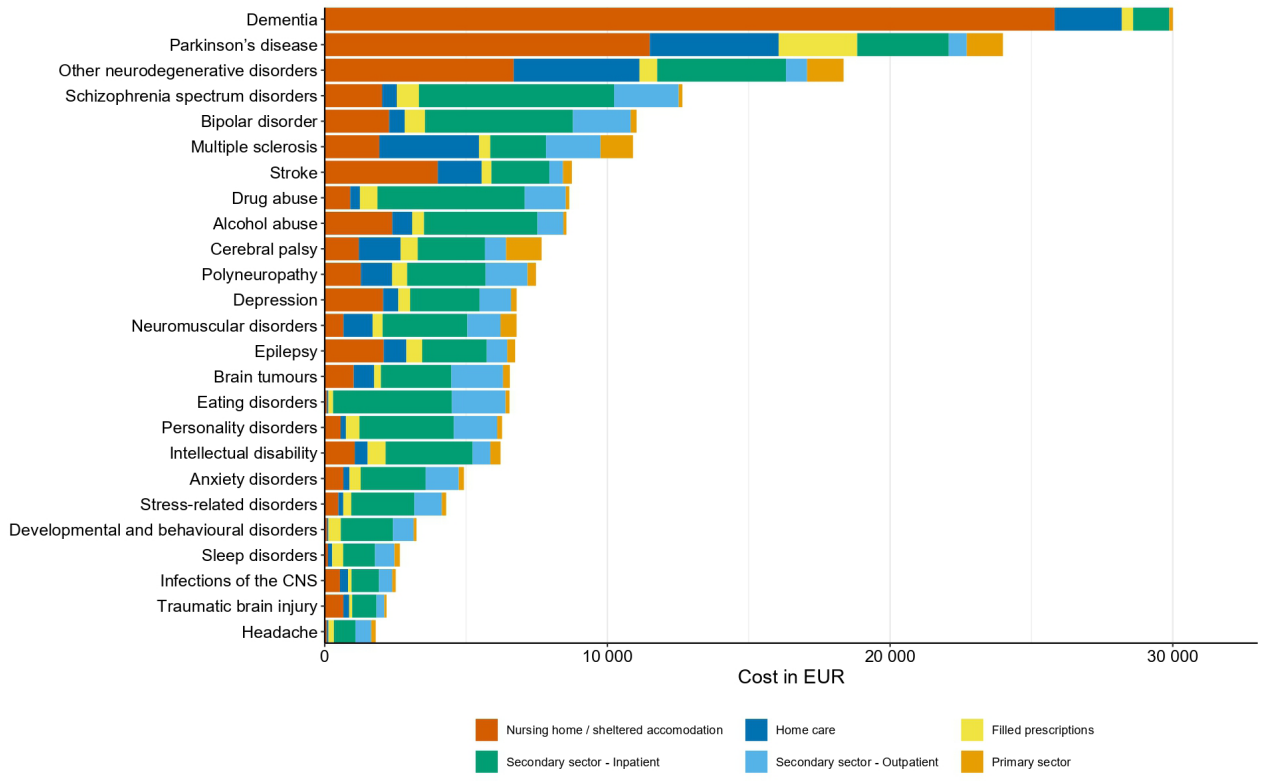

Figure 5 Attributable direct costs per person in individuals with prevalent brain disorders in Denmark in 2015 (in 2015 prices) sorted from highest to lowest costs. CNS, central nervous system.

supplemental figure 3 and online supplemental table 4).

Productivity of persons with brain disorders was reduced in every group of brain disorders. The total indirect costs in 2015 were $€ 11.2$ billion in persons with any brain disorder, mostly due to loss of productivity associated with illness (€10.9 billion) and less due to loss of productivity due to premature death ( $€ 0.3$ billion). Specifically, lost productivity was $€ 3.2$ billion in persons with stress-related disorders, $€ 2.9$ billion in persons with depression and $€ 2$.2 billion in persons with alcohol abuse. Finally, we found that the indirect costs were largely made up of costs due to lost productivity in patients living with illness, while costs due to lost productivity due to premature death contributed little (figure 6 and online supplemental table 5).

\section{Sensitivity analyses}

Adding persons with filled prescriptions to the hospitaldiagnosed cohorts, we found that occurrence of alcohol abuse, bipolar disorder and dementia increased little, while occurrence of anxiety disorders, depression, headache, Parkinson's disease and sleep disorders increased several fold (online supplemental figure 4). Prevalence of any brain disorders increased to $30.2 \%$, and total attributable costs in these persons in 2015 were $€ 22.5$ billion,

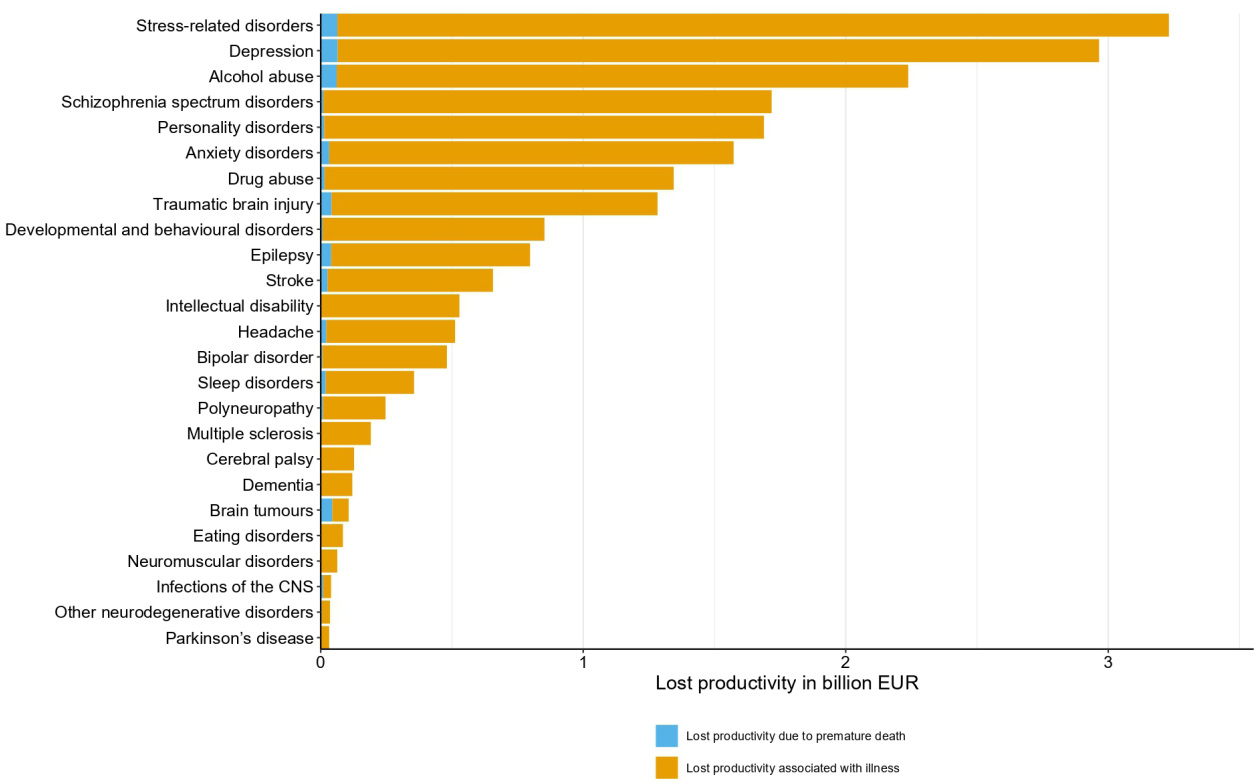

Figure 6 Total attributable indirect costs due to lost productivity in persons with prevalent brain disorders in Denmark in 2015 (in 2015 prices) sorted from highest to lowest costs. CNS, central nervous system. 
of which direct costs were $€ 6.5$ billion and indirect costs were $€ 16.0$ billion (data not shown).

In the OLS regression, we accounted for comorbid brain disorders when estimating per-person costs associated with each brain disorder. We found that dementia $(€ 23 \mathrm{~K})$ and Parkinson's disease $(€ 17 \mathrm{~K})$ were associated with the highest per-person additional direct cost of illness after adjustment for comorbid brain disorders (online supplemental figure 5). Of note, removing outliers (the 99\% percentile) changed results considerably, indicating that the $1 \%$ of persons with highest costs of illness contributed a considerable share of the total costs.

\section{DISCUSSION}

We performed a study of occurrence, mortality and cost of hospital-diagnosed brain disorders using high-quality, individual-level data. Brain disorders were common: one in five persons in Denmark had prevalent brain disorders in 2015. We found the most prevalent disorders to be traumatic brain injury, stress-related disorders and depression, whereas the disorders with the highest incidence were stress-related disorders, depression and stroke. One-year mortality was fivefold increased in persons with any brain disorder and was increased in persons with any type of brain disorder. The total attributable direct costs of persons with any brain disorder were more than $€ 5$ billion. The more common brain disorders-depression, dementia and stroke-accounted for the highest total attributable direct costs among persons with prevalent disorders. Attributable direct costs per person were highest in persons with dementia and Parkinson's disease. The total attributable indirect costs due to loss of productivity in persons with any prevalent brain disorder were twice as high as direct costs.

Even though our findings are based on high-quality population-based registries, some limitations should be considered when interpreting our findings. We may have underestimated the prevalence, incidence and total cost of non-severe brain disorders, as some patients were treated solely in general practice, or were undiagnosed or untreated. This is especially relevant for disorders that are mainly treated in primary care, or not treated at all, and therefore, were not captured in our main analyses such as anxiety, ${ }^{22}$ headache ${ }^{23}$ and sleep disorders. ${ }^{24}$ We addressed this in a sensitivity analysis that also identified patientbased filled prescriptions for relevant medications.

We estimated the period prevalence among living persons who had been diagnosed with brain disorders during the preceding 20 years, even though some disorders may be reversible. We chose this approach as a period with severe disease may affect future income and use of healthcare services.

We described non-mental comorbidity as the proportions of persons in each cohort previously diagnosed with diseases from the CCI covering 19 groups of disorders. CCI score was used to adjust for confounding in our mortality analyses, and as CCI score is an aggregated measure of comorbidity we cannot rule out residual or unmeasured confounding in our estimates of HRs of death. ${ }^{171825}$

While we had detailed data on direct costs, we lacked information on municipally supported rehabilitation, assistance supplies and transportation costs related to treatment and rehabilitation. Similarly, our cost analyses did not include intangible costs (eg, due to decreased quality of life) and costs of informal care provided by relatives, which may be considerable in conditions such as dementia. ${ }^{26}$ Yet, we included costs of nursing homes, sheltered accommodation and home nursing, and we found the annual cost per person with dementia $(€ 30 \mathrm{~K})$ similar to that previously reported in developed countries. ${ }^{27} 28$

In estimating the indirect costs (ie, loss of productivity) of illness and premature death, we applied the human capital approach. In the literature, this approach has been discussed and among others it has been argued that application of the human capital approach leads to an overestimation of the productivity costs. Hence, alternative methods like the friction cost method have been proposed. ${ }^{19}$ The idea behind the friction cost method is that the amount of production lost due to disease depends on the time (friction period) organisations need to restore the initial production level. Friction periods will differ by industry, type of work and the challenge is to estimate relevant friction periods, but application of the friction cost method leads to lower productivity cost estimates. ${ }^{19}$ Taking these considerations into account, we present our indirect cost estimates separately (figure 6) making it possible to assess the results without inclusion of the indirect costs.

Of note, our study described the cost of illness in patients with brain disorders, but did not isolate the cost of the disease itself as patients with brain disorders are known to have a high load of comorbidity. ${ }^{29-31}$

We estimated the prevalence and incidence of any brain disorder using individual-level data, which allowed us to capture concurrent brain disorders, ${ }^{29}$ opposed to the prior studies based on literature reviews that included a mix of hospital-diagnosed disorders and disorders reported in population surveys. ${ }^{35}$ Beside using different eligibility criteria, double counting of individuals with concurrent brain disorders may explain the previously reported total 1-year prevalence of brain disorders of $\sim 50 \%$ (260 million affected among 514million population in Europe), ${ }^{3}$ which is markedly higher than what we found despite including prevalent disorders during a 20-year period. ${ }^{89}$ Compared with the reported prevalence of separate disorders, we found markedly lower prevalence of anxiety (1.7\% vs $12 \%)$, headache $(1.7 \%$ vs $10 \%)$, depression $(3.2 \%$ vs $6.5 \%)$ and sleep disorders $(1.1 \%$ vs $8.7 \%$ ), despite the longer lookback in our study (20years vs 1-year prevalence). ${ }^{3}$ This may be explained by different data sources, as we in the main analyses only included persons with hospital-diagnosed disorders. Importantly, when we included persons with filled prescriptions in sensitivity analyses, the prevalence increased considerably 
indicating that we underestimated the occurrence of these disorders in our main analyses.

A recent Danish study reported a 2.5-fold increased mortality rate in persons with hospital-diagnosed mental disorders compared with persons from the general population, ${ }^{32}$ which is markedly lower than mortality of any brain disorders in our study-likely explained by our use of different length of follow-up (ie, long-term as opposed to 1 year).

We found that the total attributable direct and indirect costs of brain disorders in Denmark in 2015 were $€ 16.4$ billion, equivalent to $5.9 \%$ of the Danish GDP $\left(€ 273\right.$ billion in 2015). ${ }^{33}$ This is only slightly higher than the recently reported costs of mental illness alone of $€ 15$ billion in Denmark in 2015 corresponding to $5.4 \%$ of the GDP. ${ }^{5}$ However, when we included persons identified from filled prescriptions in addition to hospitalbased diagnoses in sensitivity analyses, the prevalence increased and total attributable costs of any brain disorders increased substantially, indicating that the costs may be higher than previously estimated when not restricting to hospital-diagnosed persons. ${ }^{35}$

Finally, previous Danish studies of selected brain disorders reported lower total costs of disorders such as dementia, ${ }^{26}$ stroke, ${ }^{34}$ Parkinson's disease ${ }^{35}$ and epilepsy. ${ }^{36}$ These studies did not include costs of home nursing and nursing homes, and when accounting for that, our findings are comparable. ${ }^{2634-36}$

As the already large burden of brain disorders is expected to increase in the future,${ }^{6}$ prevention and effective early intervention are essential. ${ }^{5}$ The potential to prevent stroke, infections of the central nervous system, and mental disorders is established, whereas the potential to prevent other neurological disorders remains unclear. ${ }^{37}$ As comorbidity load is substantial in persons with brain disorders, cost of illness may be reduced by preventing and improving treatment of comorbid disorders. ${ }^{31}$

We found that one in five persons alive in Denmark had been diagnosed with a brain disorder. One-year mortality was fivefold increased in persons with an incident brain disorder. Mortality was increased in every group of brain disorders, underscoring the illness of these patients. The severity also was reflected in the very high cost of illness in persons with brain disorders, with total attributable costs of $€ 16.4$ billion in Denmark in 2015, including direct costs of $€ 5.2$ billion and indirect costs of $€ 11$.2 billion.

Occurrence of brain disorders is expected to increase in the future. As brain disorders already use a large proportion of healthcare resources and come with high indirect costs, effective prevention and intervention strategies must be developed.

Twitter Søren Viborg Vestergaard @epi_viborg and Christian Fynbo Christiansen @ ChristianFynbo

Acknowledgements We are grateful to the Board of Clinical Specialists in Neurology and Psychiatry for its invaluable input on the definitions of brain disorders and its feedback on preliminary analyses. Specifically, we would like to thank Professor Grethe Andersen, Professor Ulrik Becker, Professor Niels Bilenberg, Associate Professor Jakob Christensen, Professor Per Fink, Professor David Gaist, Professor Poul Jørgen Jennum, Associate Professor Nils Koch-Henriksen, Professor Jørgen Feldbæk Nielsen, Professor Søren Dinesen Østergaard, and Professor John Rosendahl Østergaard for providing great clinical expertise concerning our codebook. Also, we are grateful for the contributions of Anne Staub Rasmussen to the first version of the codebook. Thanks to Professor John McGrath for input on the project and inspiration to visual presentation of the data. Finally, a huge thanks to Helle Vester for great project management and for neat proofreading of the manuscript.

Contributors CFC and HTS contributed to the study conception. CFC, HTS, NS, J0, SS, TBR and SVV designed the study and wrote a statistical analyses plan. NS, $\mathrm{JO}$ and SS outlined the economic methods, and SS and JO performed the data management and analyses of the economic data. TBR performed the remaining data management and analyses, and performed all final analyses. All authors interpreted the results, and TBR, SVV and CFC visualised the data. SVV drafted the first manuscript, and all authors revised the manuscript and approved the final version. All authors agree to be accountable for all aspects of the work.

Funding This work was supported by a grant from Lundbeckfonden (grant no. R248-2017-521).

\section{Competing interests None declared.}

Patient consent for publication Not required.

Ethics approval The study was approved by the Danish Data Protection Agency through registration at Aarhus University (record number 2016-051-000001/603). According to Danish legislation, no approval from an ethics committee or informed consent from patients is required for registry-based studies.

Provenance and peer review Not commissioned; externally peer reviewed.

Data availability statement Data may be obtained from a third party and are not publicly available. Data are available as presented in the paper and in the Supporting Information files. According to Danish legislation, our approvals to use the Danish data sources for the current study do not allow us to distribute or make patient data directly available to other parties. Data access and information about availability is accessible through Statistics Denmark (website: https://www.dst.dk/ en/TilSalg/Forskningsservice e-mail: dst@dst.dk).

Supplemental material This content has been supplied by the author(s). It has not been vetted by BMJ Publishing Group Limited (BMJ) and may not have been peer-reviewed. Any opinions or recommendations discussed are solely those of the author(s) and are not endorsed by BMJ. BMJ disclaims all liability and responsibility arising from any reliance placed on the content. Where the content includes any translated material, BMJ does not warrant the accuracy and reliability of the translations (including but not limited to local regulations, clinical guidelines, terminology, drug names and drug dosages), and is not responsible for any error and/or omissions arising from translation and adaptation or otherwise.

Open access This is an open access article distributed in accordance with the Creative Commons Attribution Non Commercial (CC BY-NC 4.0) license, which permits others to distribute, remix, adapt, build upon this work non-commercially, and license their derivative works on different terms, provided the original work is properly cited, appropriate credit is given, any changes made indicated, and the use is non-commercial. See: http://creativecommons.org/licenses/by-nc/4.0/.

\section{ORCID iDs}

Søren Viborg Vestergaard http://orcid.org/0000-0002-8445-7758

Thomas Bøjer Rasmussen http://orcid.org/0000-0003-0120-1712

Sandra Stallknecht http://orcid.org/0000-0002-1721-3665

Niels Skipper http://orcid.org/0000-0001-5766-4420

Henrik Toft Sørensen http://orcid.org/0000-0003-4299-7040

Christian Fynbo Christiansen http://orcid.org/0000-0002-0727-953X

\section{REFERENCES}

1 GBD 2015 Neurological Disorders Collaborator Group. Global, regional, and national burden of neurological disorders during 19902015: a systematic analysis for the global burden of disease study 2015. Lancet Neurol 2017;16:877-97.

2 Whiteford HA, Ferrari AJ, Degenhardt L, et al. The global burden of mental, neurological and substance use disorders: an analysis from the global burden of disease study 2010. PLoS One 2015; 10:e0116820. 
3 Gustavsson A, Svensson M, Jacobi F, et al. Cost of disorders of the brain in Europe 2010. Eur Neuropsychopharmacol 2011;21:718-79.

4 Olesen J, Gustavsson A, Svensson M, et al. The economic cost of brain disorders in Europe. Eur J Neurol 2012;19:155-62.

5 OECD EU. Health at a glance: Europe 2018: state of health in the EU cycle. Paris/European Union,Brussels, 2018. Available: https://doi. org/10.1787/health_glance_eur-2018-en

6 Bloom DE, Cafiero ET, Jané-Llopis E, et al. The global economic burden of non-communicable diseases. Geneva: World Economic Forum, 2011. http://apps.who.int/medicinedocs/documents/ s18806en/s18806en.pdf

7 Trautmann S, Rehm J, Wittchen H-U. The economic costs of mental disorders: do our societies react appropriately to the burden of mental disorders? EMBO Rep 2016;17:1245-9.

8 Sørensen HT. Global burden of neurological disorders: challenges and opportunities with the available data. Lancet Neurol 2019;18:420-1.

9 Vigo D, Thornicroft G, Atun R. Estimating the true global burden of mental illness. Lancet Psychiatry 2016;3:171-8.

10 Schmidt M, Schmidt SAJ, Adelborg K, et al. The Danish health care system and epidemiological research: from health care contacts to database records. Clin Epidemiol 2019;11:563-91.

11 Heide-Jørgensen U, Adelborg K, Kahlert J, et al. Sampling strategies for selecting general population comparison cohorts. Clin Epidemiol 2018;10:1325-37.

12 Schmidt M, Schmidt SAJ, Sandegaard JL, et al. The Danish nationa patient registry: a review of content, data quality, and research potential. Clin Epidemiol 2015;7:449-90.

13 Andersen JS, Olivarius NDF, Krasnik A. The Danish National health service register. Scand J Public Health 2011;39:34-7.

14 Pottegård A, Schmidt SAJ, Wallach-Kildemoes H, et al. Data resource profile: the Danish national prescription registry. Int $J$ Epidemiol 2017;46:798-98f.

15 Statistics Denmark. Documentation of statistics. Available: https:// www.dst.dk/en/Statistik/dokumentation/documentationofstatistics [Accessed 12 Dec 2019].

16 Ankjaer-Jensen A, Rosling P, Bilde L. Variable prospective financing in the Danish Hospital sector and the development of a Danish casemix system. Health Care Manag Sci 2006;9:259-68.

17 Charlson ME, Pompei P, Ales KL, et al. A new method of classifying prognostic comorbidity in longitudinal studies: development and validation. J Chronic Dis 1987;40:373-83.

18 Thygesen SK, Christiansen CF, Christensen S, et al. The predictive value of ICD-10 diagnostic coding used to assess Charlson comorbidity index conditions in the population-based Danish national Registry of patients. BMC Med Res Methodol 2011;11:83.

19 Drummond M, Sculpher MJ, Claxton K, et al. Methods for the economic evaluation of health care programmes. 3 edn. Oxford: Oxford University Press, 2005.

20 Drummond MF, McGuire A. Economic evaluation in health care : merging theory with practice. New York: Oxford University Press, 2001.
21 Wickham H, Averick M, Bryan J, et al. Welcome to the Tidyverse. J Open Source Softw 2019;4:1686.

22 Alonso J, Angermeyer MC, Bernert S, et al. Prevalence of mental disorders in Europe: results from the European study of the epidemiology of mental disorders (ESEMeD) project. Acta Psychiatr Scand Suppl 2004;420:21-7.

23 Stovner LJ, Andrée C. Prevalence of headache in Europe: a review for the Eurolight project. J Headache Pain 2010;11:289-99.

24 Kerkhof GA. Epidemiology of sleep and sleep disorders in the Netherlands. Sleep Med 2017;30:229-39.

25 Schneeweiss S, Seeger JD, Maclure M, et al. Performance of comorbidity scores to control for confounding in epidemiologic studies using claims data. Am J Epidemiol 2001;154:854-64.

26 Frahm-Falkenberg S, Ibsen R, Kjellberg J, et al. Health, social and economic consequences of dementias: a comparative national cohort study. Eur J Neurol 2016;23:1400-7.

27 Schaller S, Mauskopf J, Kriza C, et al. The main cost drivers in dementia: a systematic review. Int $J$ Geriatr Psychiatry 2015;30:111-29.

28 Cantarero-Prieto D, Leon PL, Blazquez-Fernandez C, et al. The economic cost of dementia: a systematic review. Dementia 2019:147130121983777.

29 Plana-Ripoll O, Pedersen CB, Holtz Y, et al. Exploring comorbidity within mental disorders among a Danish national population. JAMA Psychiatry 2019;76:259-70.

30 Barnett K, Mercer SW, Norbury M, et al. Epidemiology of multimorbidity and implications for health care, research, and medical education: a cross-sectional study. Lancet 2012;380:37-43.

31 Lawrence D, Hancock KJ, Kisely S. The gap in life expectancy from preventable physical illness in psychiatric patients in Western Australia: retrospective analysis of population based registers. BMJ 2013;346:f2539.

32 Plana-Ripoll O, Pedersen CB, Agerbo E, et al. A comprehensive analysis of mortality-related health metrics associated with mental disorders: a nationwide, register-based cohort study. Lancet 2019;394:1827-35.

33 Statistics Denmark. Annual national accounts. Available: https:// www.dst.dk/en/Statistik/emner/nationalregnskab-og-offentligefinanser/aarligt-nationalregnskab [Accessed 12 Dec 2019].

34 Jennum P, Iversen HK, Ibsen R, et al. Cost of stroke: a controlled national study evaluating societal effects on patients and their partners. BMC Health Serv Res 2015;15:466-66.

35 Jennum P, Zoetmulder M, Korbo L, et al. The health-related, social, and economic consequences of parkinsonism: a controlled national study. J Neurol 2011;258:1497-506.

36 Jennum P, Sabers A, Christensen J, et al. Welfare consequences for people with epilepsy and their partners: a matched nationwide study in Denmark. Seizure 2017;49:17-24.

37 Arango C, Díaz-Caneja CM, McGorry PD, et al. Preventive strategies for mental health. Lancet Psychiatry 2018;5:591-604.

38 Rudd AG, Wolfe CDA, Howard RS. Prevention of neurological disease in later life. $J$ of Neurosurg Psychiatry 1997;63:39S-52. 